\title{
La significación del diccionario de González de Mendoza (1761-1763) en la historia de la lexicografía bilingüe hispanofrancesa
}

\author{
The Relevance of Conzález de Mendoza's \\ Dictionary (1761-1763) in the History of \\ Spanish-French Lexicography
}

Manuel Bruña Cuevas

Filología Francesa

Universidad de Sevilla

C/ Palos de la Frontera, s/n. Sevilla, 41004

mbruna@us.es

Orcid ID 0000-0002-5281-8256

Resumen: Este trabajo pretende revalorizar la importancia del diccionario bilingüe $(1761-1763)$ de González de Mendoza en la historia de la lexicografía hispanofrancesa. Mediante su análisis y comparación con otros diccionarios similares de su siglo, mostramos que su pretendido defecto de composición -la gran desproporción existente entre la parte español-francés y la parte francés-español- es justamente su mejor baza. Esa desproporción deriva de la adaptación del autor a dos objetivos: primeramente, ofrecer un diccionario que respondiera a las necesidades reales de la mayoría de quienes consultaban diccionarios bilingües en su época; en segundo lugar, asegurar la venta de su obra gracias a un precio moderado que contrarrestara la competencia del diccionario hispanofrancés más reputado de su tiempo. Concluimos que el diccionario de González de Mendoza es una propuesta muy original para su época, principalmente por su parte español-francés, precursora de los diccionarios manuales que triunfarán, sobre todo, desde comienzos del siglo XIX.

Palabras clave: González de Mendoza. Francisco Sobrino. Torre y Ocón. Antonio María Herrero. Lexicografía bilingüe.
RECIBIDO: 19 DE JULIO DE 2016 ACEPTADO: 24 DE OCTUBRE DE 2016
Abstract: This paper aims to revalue the importance of González de Mendoza's bilingual dictionary (1761-1763) in the history of Spanish-French lexicography. Through its analysis and comparison with other similar dictionaries of his century, we show that its claimed defect of composition -the great disproportion between the Spanish-French part and the French-Spanish part- is precisely its best asset. This disparity stems from the adaptation of the author to two objectives: firstly, to provide a dictionary responding to the real needs of the majority of its potential readers; secondly, to ensure the sale of his work thanks to a moderate price. We conclude that the dictionary of González de Mendoza is a very original proposal for its time, mainly because of its Spanish-French part, forerunner of the manual dictionaries that will succeed since the early nineteenth century.

Keywords: González de Mendoza. Francisco Sobrino. Torre y Ocón. Antonio María Herrero. Bilingual Lexicography. 
N icolás González de Mendoza es autor de uno de los diccionarios bilingües hispanofranceses que jalonan el siglo XVIII: el Diccionario general de las dos lenguas española y francesa. Editado en Madrid por Andrés Ortega, la obra se compone de dos partes; la primera, español-francés, salió a luz en 1761; en 1763 lo hizo la segunda, francés-español.

El panorama lexicográfico hispanofrancés del siglo XVIII es, antes y después de la obra de González de Mendoza, bastante nutrido para la época: con anterioridad a 1761, ya habían aparecido en el mismo siglo los diccionarios de Francisco Sobrino (Bruselas 1705), Francisco de la Torre y Ocón (Madrid 17281731), Antonio María Herrero (Madrid 1743-1744) y Pierre de Séjournant (París 1759). ${ }^{1}$ El de González de Mendoza era pues el tercer diccionario de este género que se editaba en España en un espacio de tiempo relativamente corto, por lo que cabe preguntarse qué pudo impulsar al autor a lanzarlo, es decir, qué ofrecía González de Mendoza para poder competir con éxito, primeramente, frente a los diccionarios ya publicados en Madrid, pero también frente a los que, aunque publicados fuera de España, se vendían asimismo en este país.

Dado que las dos partes de la obra de González de Mendoza no se editaron el mismo año y que, como veremos, ambas difieren en su planteamiento, comenzaremos respondiendo a las anteriores preguntas centrándonos primero en la parte español-francés y en lo que sabemos sobre el autor, para pasar luego al análisis de la segunda parte. Nuestras conclusiones resumirán el papel desempeñado por este diccionario en la historia lexicográfica hispanofrancesa.

1. Descartamos de nuestro recuento los vocabularios alfabéticos incorporados a ciertas obras didácticas, ya que, pese a que algunos puedan alcanzar una cierta extensión, ni en calidad ni en cantidad llegan a tener la complejidad de los verdaderos diccionarios. Es el caso, por ejemplo, del vocabulario unidireccional francés-español incluido en la Grammaire et dictionnaire françois et espagnol (1701), de Maunory, o del bidireccional de la Gramática nueva española y francesa (1717), de Francisco Sobrino. Y, por supuesto, excluimos igualmente de nuestro recuento los vocabularios temáticos (ver Bruña Cuevas 2008a; Carranza Torrejón; Alvar Ezquerra 2013), muy diferentes en su concepción de los diccionarios alfabéticos. Sobre los diccionarios hispanofranceses del siglo XVIII, ver Niederehe (1987; 1988), Cazorla Vivas (2002; 2014) y Alvar Ezquerra (2005, 3-6). Se hallará una historia de la producción lexicográfica -alfabética y temática- que incluía el francés y el español en los siglos XVI a XIX, así como una completa bibliografía de los trabajos académicos que se le han dedicado, en Bruña Cuevas (2008a). Sobre el diccionario de González de Mendoza, ver Niederehe (1987, 22-23; 1988, 38), Cazorla Vivas (2002, 177-92; 2008), Alvar Ezquerra (2005, 4-5), Bruña Cuevas (2008a, 52-53; 2015a, 358-59; 2015b, 79-81; 2016a, 101-03).

2. El tercero en términos absolutos, dado que ninguno de los diccionarios hispanofranceses de los siglos XVI y XVII (Henricus Hornkens 1599, Jean Pallet 1604, César Oudin 1607, Girolamo Vittori 1609, Trognesius 1639) se había editado o reeditado en España (Bruña Cuevas 2008b). Sobre la lexicografía hispanofrancesa de los siglos XVI y XVII, ver sobre todo Pablo Núñez (2008; 2010) y Zuili (2014; 2016, 113-62). 


\section{LA PARTE ESPAÑOL-FRANCÉS}

Aunque publicada finalmente en 1761, González de Mendoza quizá tuviera ya prácticamente terminada la parte español-francés en 1760, dado que la obra obtiene la licencia del Consejo el 26 de noviembre de ese año, debiendo ser anterior la fecha de solicitud. Esto significa que, cuando el autor empezó a redactarla, aún no había aparecido uno de los diccionarios a los que nos hemos referido: el Nouveau Dictionnaire espagnol-françois et latin, de Séjournant, se publica en 1759. Por consiguiente, González de Mendoza, hacia esa fecha, hubo de analizar la situación lexicográfica hispanofrancesa partiendo de que el diccionario bidireccional de Torre y Ocón (El maestro de las dos lenguas. Diccionario español y francés, francés y español) no estaba ya en el mercado -no se había vuelto a publicar desde 1728-1731- y de que poco tenía que temer de la competencia del Diccionario universal francés y español de Herrero; aunque la única edición de este último (1743-1744) todavía se publicitó en la Gaceta de Madrid hasta 1758 (n. ${ }^{\circ} 45$ de 7 de noviembre, página 360), se trataba de una obra solo unidireccional francés-español: incluso para quienes hubieran adquirido la obra de Herrero, un diccionario español-francés como el que proponía González de Mendoza podría ser un complemento deseado. La verdadera competencia que tendría que afrontar su obra sería, por tanto, la del diccionario bidireccional de Sobrino (Diccionario nuevo de las lenguas española y francesa / Dictionnaire nouveau des langues françoise et espagnole), cuya última edición databa solo de 1751. Se trataba, además, de un competidor temible, dada su magnífica reputación y venta, asegurada por una potente difusión editorial. Pese a todo, es evidente que tanto González de Mendoza como su editor vieron posibilidades de rivalizar con el Sobrino.

Para entender por qué, conviene previamente analizar lo que podemos entrever sobre la posición social de González de Mendoza. La realidad es que poco sabemos sobre su vida, salvo que hizo estudios en Salamanca, quizá sin culminarlos a juzgar por lo que dice en su dedicatoria al también universitario salmantino Juan Miguel de Uztáriz. ${ }^{3}$ Puede que posteriormente fuera militar o marino, o que, por lo menos, estuviera muy en contacto con esas acti-

3. Con la modestia retórica propia de las dedicatorias, declara en la suya que, si hubiera sabido cuando estaba en la universidad de Salamanca que llegaría el día en que tendría que redactarla, "no me huviera separado de aquella Palestra de las Ciencias, sin hurtarle algo de lo que influye, para hallarme aora menos desproporcionado; pero haviendome venido con la misma pobreza de entendimiento, de ciencia, y de espiritu que fui...”. 
vidades, ${ }^{4}$ ya que, en su obra, a menudo cambia y desarrolla las fuentes de que se inspira cuando se trata de artículos referentes a tales campos. ${ }^{5}$ Quizá por esa actividad pasara cierto tiempo en Andalucía, dado que sus referencias a usos léxicos andaluces son bastantes en la segunda parte de su obra, francésespañol, ${ }^{6}$ aunque también en la primera hay alusiones a ese territorio. Así, para una de las acepciones de señal, el ejemplo que pone es "Yo ajusto una calesa para Cadiz, en treinta pesos...”; y he aquí la definición en español para Zalea: "Zalea, llaman en Andalucìa à un pellejo de carnero con lana". Su leísmo parece descartar que fuera de origen andaluz -aunque pudo adquirirlo después de niño-, pero, en todo caso, el siguiente artículo de la parte francésespañol parece destilar una cierta nostalgia de momentos quizá vividos en sus tiempos mozos:?

Brandilloire. Columpio, que en Andalucia, Provincia dilatada de España, se compone de dos buenas sogas retorcidas, puestas en una viga de un sobrado de la casa, que es una pieza alta, y capàz, y de cuerda à cuerda, ò soga, se pone una tabla de tres quartas de ancho, afianzada de uno, y otro extremo de la tabla, y en esta se sienta la gente moza, que regularmente son mugeres, con los pies pendientes en el ayre, y entre dos personas le dàn à el columpio cada una su bamboleo, $y$ assi se estàn recibiendo ayre toda una tarde.

Por esas mismas razones profesionales a las que nos hemos referido antes, pudo igualmente pasar un tiempo en Galicia, a la cual hay una alusión en el artículo Saín, construido a partir únicamente de su propia competencia, dado que no coincide en nada con el correspondiente artículo en los diccionarios monolingües o bilingües anteriores al suyo: "Sain, aceyte de sardinas, y algun otro pescado semejante de mar, con que se alumbran los pobres en Galicia. De l'buile de sardines".

Sea como fuere, González de Mendoza residía en Madrid cuando publicó su diccionario ${ }^{8}$ y fácil es vislumbrar que, frente a un Torre y Ocón-que

4. ¿Ejerció González de Mendoza una actividad profesional al servicio de Uztáriz? De ser así, y dado que este tuvo negocios en Cádiz, puede que allí residiera González de Mendoza durante un tiempo. Por otro lado, Uztáriz nació en 1720; puesto que González de Mendoza coincidió con él como estudiante en la Universidad de Salamanca, cabe pensar que ambos tuvieran una edad similar.

5. Entre otros muchos casos, ver Rancho, Zarpar, Zozobrar, Entablement, Peloton, Virer...

6. Ver los artículos Blanchir, Brandilloire, Bretteur, Chambre, Chiche, S'impatroniser, Passage, Pite, Réjouissance.

7. Respetamos escrupulosamente en todas nuestras citas las grafías y la puntuación del original.

8. Tanto en portada como en los preceptivos documentos legales que figuran en los preliminares de su obra, su nombre aparece acompañado de la mención "vecino de esta Corte". 
adorna la portada de su obra con los títulos de "Presbitero Capellan del Real, y Supremo Consejo de las Indias; Ministro Titular, y Traductor de Lenguas de la Santa Suprema, y General Inquisicion” y era autor-traductor de la obra Economía general de la casa de campo (1720) - o frente a un Herrero -famoso médico, autor de diversas obras propias y traducidas-, su relevancia social debía de ser mucho más modesta. Nos parece factible imaginar que la enseñanza del francés fuera la principal o una de las actividades fundamentales con que se ganaba la vida en torno a 1761. Así se entendería que, al concebir su diccionario, hubiera partido del punto de vista de un maestro de lenguas, conocedor de las dificultades que había de afrontar su clientela de principiantes en el aprendizaje del francés y, por tanto, atento a resolverlas con su obra. Dicho de otro modo, tanto Torre y Ocón como Herrero publicaron sus diccionarios después de haber traducido sendas obras del francés y nunca fueron, que sepamos, maestros de idiomas; la orientación de sus diccionarios responde por ello más bien a las necesidades de un traductor o de un usuario con nivel avanzado de francés9 (de hecho, como ya hemos dicho, Herrero no publicó una parte español-francés) que a las del mero principiante. Bien podía González de Mendoza, por tanto, pensar en un diccionario novedoso en su orientación y adaptado al público con el que estaba acostumbrado a tratar como docente. Solo que esto aún no bastaba para contrarrestar la rivalidad de su verdadero competidor: el diccionario de Sobrino.

Sobrino fue el gran maestro de lengua española en la Bruselas de su tiempo y su caso confirma lo que acabamos de sugerir en cuanto al diccionario de Mendoza. Comenzó publicando una gramática del español (1697), a la que fue añadiendo en los años siguientes un diccionario (1705), unos diálogos (1708) y un manual de correspondencia (1720). Su diccionario se inscribe, pues, en un completo programa de enseñanza del español. No queremos decir con esto que el diccionario de Sobrino sea elemental ni pensado solo para principiantes; es, al contrario, una obra rica y compleja. Pero no por ello -como no podía ser menos dada su actividad profesional- olvidó el autor que también podría ser útil a los poco versados en francés o español; de ahí que lo fuera orientando cada vez más en esta dirección a lo largo de sus primeras reediciones. Si se compara la primera edición con las siguientes, se nota un progresi-

9. Esto es especialmente obvio en el caso de Herrero; la propia fuente principal que escogió como guía para su diccionario es ya evidencia suficiente de ello (Bruña Cuevas 2006, 136-37). Pero no deja de ser cierto también en el caso de Torre y Ocón (Bruña Cuevas 2016b). 
vo enriquecimiento en varios aspectos,$^{10}$ particularmente en lo didáctico, pese a lo mucho que ya lo era la primera: el gran número de frases o sintagmas de contextualización de los lemas que la primera ofrecía -con el fin de ilustrar las variaciones en género y número o las correspondientes a la morfología verbalse ve todavía incrementado en las posteriores. Compárese el número de entradas sobre los lemas Limpio y Laisser en 1705 y en 1721 :

Limpia / No ser una cosa agua limpia / Límpio / En límpio / Sacar en limpio / Limpio de calentura / Limpio / Limpio de polvo y de paja. (Sobrino 1705)

(Además de las entradas de 1705) Ser limpia, esto se dize de una muger / Es limpia, son limpias / Estàr limpia, esto se dize de qualquiera cosa que sea / Esta casa està limpia / La camisa està limpia / Las corbatas estàn limpias / Ser limpio, esto se dize de un hombre / Es limpio, son limpios / Estàr limpio, esto se dize de qualquiera cosa que sea / El bestido està limpio / El sombrero està limpio / Los çapatos estàn limpios / Todo està limpio. (Sobrino 1721)

Laisser / J'ai laissé ma bourse sur la table / Laisser un chemin à droite ou sur la droite, prendre à gauche / Laissez-le parler / Laisse-moi en paix, en repos / Laissez cela / Laissez-le faire / Se laisser tomber. (Sobrino 1705)

(Además de las entradas de 1705) Laissant / Laissé / Je laisse, tu laisses, il laisse, elle laisse / Nous laissons, vous laissez, ils laissent, elles laissent / Laissez-le aller, laissez-là [sic] aller / Laissez-le venir avec nous / Laissezmoi à repos. (Sobrino 1721)

Todo esto muestra, como hemos señalado, que el diccionario de Sobrino, pese a su amplitud, pese a su carácter parcialmente enciclopédico, no solo no olvidó a los principiantes, sino que los puso desde el principio, y sobre todo desde $1721,{ }^{11}$ en el centro de sus preocupaciones. Pese a todo, algún inconve-

10. El diccionario se estabiliza a partir de la edición de 1744, aunque todavía incluye ciertas innovaciones en la de 1751. La última edición de 1760 es, en cambio, prácticamente idéntica a la anterior, salvando la corrección de algunas erratas.

11. Solo en un punto sobrepasa en lo didáctico la primera edición del diccionario de Sobrino (1705) a sus ediciones posteriores: la de 1705 es la única que incorporaba (páginas 351-411 de la parte francés-español) una de las herramientas más usadas en todos los tiempos para la enseñanza de idiomas, o sea, un vocabulario temático. Que desaparezca desde la segunda edición (1721) puede deberse a los aumentos que esta incluía o simplemente a que ya el autor había añadido otra nomenclatura, mucho más adaptada a los principiantes, en sus Diálogos nuevos en español y francés (1708). 
niente desde el punto de vista didáctico había de tener esa obra para que González de Mendoza pensara en ofrecer una alternativa.

Antes de que González de Mendoza editara su propio diccionario, es muy probable que recomendara a sus alumnos la consulta del de Sobrino por sus marcados rasgos didácticos frente a los de Torre y Ocón y Herrero. Pero sin duda se percataría de que sus discípulos debían afrontar, al manejar el Sobrino, el problema de todo principiante: si intentaban pasar de su lengua materna española al francés, querrían encontrar rápidamente un equivalente concreto para el término español que tuvieran en mente; solo que no era eso lo que muy a menudo les ofrecía Sobrino. Consciente de la polisemia característica de las lexías de una lengua natural, Sobrino solía dar para cada entrada española un variado número de equivalentes, unas veces más o menos sinonímicos y, en otros casos, adecuados para traducir correctamente las diferentes acepciones de cada término español. Así, para Airoso, Sobrino $(1751)^{12}$ proporcionaba cuatro entradas, de las que he aquí las tres primeras:

Ayroso, Beau, gracieux, agréable, gaillard.

Ayroso, De bon air, gentil, agréable.

Està ayroso, Il a bonne grace, il est agréable, il a bon air.

Para un usuario francófono, la diversidad de equivalentes franceses ofrecidos por Sobrino para airoso era provechosa; guiado por su propia competencia en francés, ese usuario podía escoger, de entre ellos, el más preciso para traducir a su lengua la acepción exacta de la voz española en el contexto donde la había encontrado. Por el contrario, esa misma diversidad de equivalentes que Sobrino proponía para airoso podía sumir en la confusión a un usuario hispanohablante. Lo ideal para alguien poco versado en una lengua extranjera, cuando consulta un lema de su lengua materna en un diccionario bilingüe, es que se le proponga una sola equivalencia; de ofrecérsele varias traducciones, como hace Sobrino en airoso, no tendrá generalmente suficiente capacidad para discernir cuál de ellas es realmente la más adecuada para el vocablo que ha buscado. Pues bien, solucionar este problema de los principiantes hispanohablantes que recurrían a un diccionario bilingüe español-francés parece ser el principio que rigió la composición de la primera parte de González de Mendoza. De hecho, así lo declara el propio autor en el prólogo de 1763

12. Fue la quinta edición del Sobrino (1751) la que siguió González de Mendoza para componer su diccionario. No fue, sin embargo, la única fuente de que se inspiró (Bruña Cuevas 2017). 
cuando afirma que la superabundancia de equivalentes o la prolijidad en las definiciones

solo sirve de embarazo, vulto de el volumen, dificultad en hallar lo que se busca, duda en la satisfaccion de el principiante, coste de papel, y Prensa, aumento en el precio de los libros, enfado en el que tiene vivo el ingenio, $\mathrm{y}$ finalmente el tiempo que en todo lo escusado và perdido.

Nuestro autor debió de ver, pues, una posibilidad de clientela entre aquellos hispanohablantes que intentaban servirse del diccionario español-francés de Sobrino y lo encontraban demasiado complejo para su nivel. Sería su labor ofrecer un diccionario fácilmente accesible para el poco adelantado en francés gracias a sus grandes caracteres (en comparación con los pequeños caracteres del diccionario de Sobrino) y, sobre todo, a su sencillez. ${ }^{13}$ Esta la logró partiendo del principio de que existía una equipolencia léxica entre la mayoría de los términos de ambos idiomas, de que a la mayor parte de los vocablos españoles solo podía corresponder legítimamente un único vocablo francés: de preferencia, el que más se le pareciera formalmente por razones etimológicas, o bien cualquier otro aunque no cumpliera esa condición, pero uno solo.

Este principio de base que atribuimos a la composición de la parte español-francés de González de Mendoza salta a la vista al echarle una simple ojeada; pero, además, por suerte para nosotros, también lo expone el autor en el interesante prólogo que encabeza esa parte:

Quiere el Español saber còmo se dice en Francès, concluir, buscalo en el Diccionario, y halla enfrente una docena de Synonomos, que la mitad de ellos (acaso) no tienen alusion con lo que busca, quiero que la tenga, como los que se siguen: concluir... Terminer, finir, dècider, resoudre, achever, conclure, que con decir esto ultimo estaba dicho lo que ello es, sin confundirlo con lo que se le parece.

Cada Synonomo de los referidos hace su papel principal en su casa, y tiene su particular, y propia significacion, todos ellos, y (quasi) quantos puede producir uno, y otro Idioma, los hallarás en este libro, pero no dupli, tripli, y quatriplicados, sino cada uno solo, haciendo su servicio donde le toca, como mas claramente se vè aqui; porque

13. Ya en su prólogo de 1761 anuncia el autor que el tipo de diccionario que ofrecía estaba planteado sobre bases distintas a las de los anteriores: "Es diferente en el methodo de todos los que hasta aora se han dado al Pùblico". 


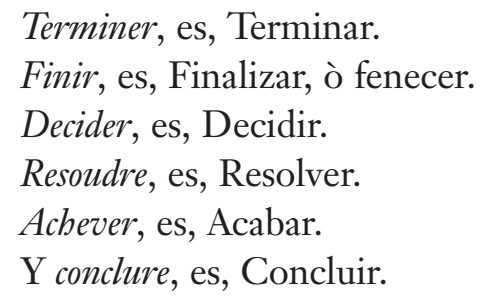

Como hemos dicho, el autor llegó a poder aplicar su principio, con más o menos fortuna y más o menos constancia, a la mayor parte de sus lemas españoles, pero, como puede suponerse, en una alta cantidad de ocasiones su principio debía fallarle por fuerza. El autor siempre fue consciente -o fue tomando conciencia a medida que componía su obra- de que ciertas voces de uno u otro idioma no tenían correspondencia léxica exacta en el otro. De hecho, también encara ya este problema en el prólogo de la primera parte:

Quiere el Español saber como se dice en Francès desemboltura; esto es, desembarazo, $y$ libertad, en el decir, $y$ hacer, $y$ vè que no tiene voz que de una vez exprima el termino: aqui es menester valerse de los Synonomos, para dàr à conocer lo que significa, verbi gracia: Hardiese, gaillardise, agilitè, adresse, Debarrasement \& livertè [sic] dans les actions \& façons de dire \& de faire.

Lejos, pues, de pretender ocultar que su principio composicional no tenía aplicación universal, el autor lo señala abiertamente en su prólogo, como acabamos de ver, pero igualmente en la propia portada de la parte español-francés, donde ya proclama, al referirse a la futura segunda parte, francés-español, que en ella "se haràn patentes todas las voces que tiene la Lengua Francesa de que carece la Española, assi como en esta [primera parte] las que tiene la Española, de que carece la Francesa". Eso es, efectivamente, lo que muestra a menudo su obra mediante el empleo de varios procedimientos.

Se decide en ciertos casos, como anunciaba en el prólogo, por la construcción de sus artículos a base de sinónimos ${ }^{14}$ ("Nube, dicese de tres modos.

14. El esquema un lema/ un solo equivalente francés es el predominante en la composición de los artículos de toda la parte español-francés. No obstante, se hace cada vez más frecuente, conforme se avanza hacia el final del tomo, que para un lema se ofrezcan varios equivalentes. Va acrecentándose asimismo (volveremos a ello) el número de lemas con varias subentradas destinadas a proporcionar ejemplos de uso contextualizado o variaciones morfológicas (Recibir / Recibido / Recibiendo / Recibiendole / Recibiendola / Reciba usted / Saliò à recibirlo, ò à recibirla / Salgamos à recibirlos, ó à recibirlas / Recibir un criado). 
Nuage, nuë, y nuée"). Solo que no podía ser este el procedimiento al que más recurriera porque hubiera dado con ello en el tipo de diccionario -el de sus predecesores del XVIII- del que aspiraba a distinguirse. De ahí que, en un intento por llamar la atención del usuario sobre aquellos vocablos españoles que, a su juicio, no disponían de equivalentes léxicos perfectos en francés, sea mucho más frecuente en su obra que vengan marcados mediante un "no ay", un "suple", un "vale" o alguna otra fórmula más compleja; que estén marcados, pues, explícitamente, como términos para los que el usuario deberá esforzarse por usar un vocablo francés cuyo significante no guarda relación morfológica alguna con la raíz española o que, siempre según él, no es una palabra que signifique exactamente lo mismo que el lema español. La verdad es que, a veces, con un simple "no ay" dejaba a su lector sin ningún socorro: "Muñeca de la mano. (no ay)"; "Zoquete de pan, (no ay) ni en otro sentido". ${ }^{15}$ Pero, en la mayor parte de las ocasiones, ofrece una alternativa francesa, por alejada que se encuentre etimológicamente de la forma española de partida: "Lindo. (no ay) Foli"; "Odio. (no ay) Haine" (en cambio, por la similitud formal, "Odioso. Odieux"). En tales ocasiones, no es raro que el autor explicite que esa voz o locución francesa, bien que alejada de la española, es la que mejor puede suplirla, la que mejor pude corresponderle en ese idioma:

Barruntar (voz baxa) (no ay) suple lo que significa Supçonner [sic], inferer, colliger quelque chose.

Ocultar (no ay) suple Cacher.

Zurriago, (no ay) suple azote. Fouet.

Luzero (no ay) llamase estrella. Etoile.

Zurrando à un muchacho, vale por. Batant un garçon.

Lampiño, que no tiene barbas. (no ay) Celui qui n'apoint [sic] de barbe.

Pantorrilla, no tiene nombre particular, dicen, lo gordo de la pierna. Le gras de la jambe.

Perol, no tiene nombre particular, sirvense del comun, que hace à muchas cosas. Chaudere [sic] grand bassin, ou poele, \&c.

Saber bien una cosa. Avoir bont [sic] gout \& saveur. Pero me sabe bien no se dice. Este pan me sabe bien. Ce pain me plait, je trouve ce pain bon.

Pesame. (no se dice). Dàr un pesame. Faire vn compliment de condoleance.

15. La fórmula empleada puede ser diferente: "Parsimonia, palabra latina, que significa economìa, no usan de ella". Compárese con lo que ofrecía Sobrino (1751): "Parsimónia, f. ésta palabras [sic] es Latina, y significa Economìa, Economie, f. épargne". 
Pero todavía no quedaban resueltas con esto todas las dificultades que entrañaba el principio lexicográfico adoptado por el autor. A veces existía parecido formal entre los significantes de dos vocablos, uno español y otro francés, pero sus significados, su frecuencia de empleo, su registro de lengua no eran coincidentes en ambos idiomas. González de Mendoza intentará, en esos casos, advertir a su lector de tales hechos al modo del docente que era, o sea, mediante la redacción de unos artículos cuya microestructura sorprende al lector moderno, pero de cuya eficacia pedagógica no cabe dudar:

Original, que no es la copia, ò retrato. Original, pero lo que viene de origen, como el pecado original, muda, y se dice Originel.

El pecado original. Le peché originel.

Copia del original. Copie de l'original.

No sè que hacerme. (dicho comun que en Francès es mas vulgar.) fe ne sai oú donner de la tête...

Picado, en sentido de ofendido, lo mismo que en Castellano. Piqué, choqué; aunque acà (chocar) no es picar, mas bien le acomoda degollar, descalabrar, corromper, y otras alusiones apodicas de jacara, que los ingenios majos han introducido pocos años hà.

Negligencia: Negligence.

Nota. En el idioma Español la negligencia propiamente es pereza, desidia, \&c. pero en el Francès à mas de esto es desprecio, es tambien desaliño, desaseo, y poco cuidado, bien que en una, y otra lengua es todo conexivo mas, ò menos [...].

Como se ve, pese a todas las dificultades que el principio de equipolencia léxica entre el francés y el español planteó a González de Mendoza, puede decirse que logró en gran medida su propósito: ofrecer a quienes intentaban expresarse en francés sin disponer de buen nivel un diccionario sencillo en aspecto y contenidos, fácilmente manejable y comprensible por ellos, menos complejo, unas veces, pero también menos escueto, en ciertos casos difíciles, que el de Sobrino. Y lo consiguió mediante los procedimientos que hemos expuesto, pero también, como no podía ser menos, mediante la supresión de los numerosísimos artículos enciclopédicos que contenía el Sobrino y de un gran número de lemas que el autor consideró poco extendidos en español.

Ni siquiera dudó nuestro autor en aminorar drásticamente uno de los principales rasgos didácticos que caracterizaban el diccionario de Sobrino. Este, en efecto, dirigía su obra tanto a usuarios de nivel avanzado en una o en las dos len- 
guas como a principiantes; pensando primordialmente en estos últimos, ofrecía para ciertos lemas, como hemos visto, un nutrido número de subentradas que recogían las variaciones morfológicas propias del lema correspondiente: género y número -en el caso de sustantivos, adjetivos y participios- o tiempo, modo y persona, en el caso de los verbos. Nada más propio que esto para un diccionario de carácter eminentemente didáctico como el de González de Mendoza, cuya parte español-francés estaba destinada primordialmente a principiantes españoles en el manejo del francés. Solo que, si nuestro autor hubiera conservado el mismo número de subentradas de tal tipo que Sobrino recogía, hubiera obtenido un grueso volumen, lo que hubiera entrado en contradicción con la apariencia de sencillez que se había propuesto conferir a esa parte de su obra. De ahí que, por instructivas que fueran para los principiantes, optara por reducir considerablemente la presencia en su obra de ese género de subentradas. ${ }^{16}$

El resultado de todo esto fue un diccionario mucho menos abultado que el de Sobrino. Frente al volumen en gran formato $(25 \mathrm{x} 19 \mathrm{~cm})$ y 601 páginas a tres columnas que contenía la parte español-francés de la edición de 1751 del Sobrino, la misma parte de González de Mendoza se presentaba en un volumen de 19.5 x 14 cm y 368 páginas a dos columnas; frente a la edición lujosa, con grabado y portada a dos tintas, del de Sobrino, la portada a una sola tinta y la falta de adornos en el diccionario de González de Mendoza. Este ofreció, por tanto, no solo un diccionario más simple, sino también más barato que el de Sobrino, lo que no debió de ser una baza menor cara a la clientela a la que iba dirigido. De hecho, el propio autor hace alusión a ello cuando dice en su primer prólogo (1761) que había conseguido "un Diccionario pequeño en el tomo, y grande en el caudal, poco que le falte, y nada que le sobre [...]; en èl hallaràs, no solo quanto de lo util encuentres en los otros, pero algo mas, aunque con tres partes menos de papel, y letras...”.

De lo dicho se deduce que lo que pretendió y consiguió en cierto modo González de Mendoza fue ofrecer lo que podríamos denominar, ante litteram,

16. Con todo, y siempre sin llegar a los extremos de Sobrino, González de Mendoza conservó una alta cantidad de casos en que ofrecía esas variantes morfológicas; cada vez más, de hecho, a medida que se avanza en la primera parte. Seguramente lo hizo así por el valor didáctico que les reconocía. Sirva de ejemplo el conjunto de entradas correspondientes al lexema neg-: Negar / Negado / Negando / Niego, niegas, niega / Negamos, negais, niegan / Ha negado / No niegue Usted / Negarà / Negaràn / Negativo / Negativa. Esta serie, no obstante, es ya una reducción de la que ofrece Sobrino (1751): Negacion / Negado / Negador / Negante / Negando / Negar / Niego, niegas, niega / Negamos, negáis, niegan / Negar à pies [sic] juntillas / Niegue usted / Por que niega usted? / No niegue usted / Ha negado / Ha negado? / Negarà / Negaràn / Negativa / Negativo. 
un diccionario manual. De hecho, tiene un formato similar al del primer diccionario de la historia lexicográfica hispanofrancesa que se presenta en su título como "portátil y manual" -el unidireccional Diccionario nuevo portatil, y manual Francés-Español (1795), de Diego Antonio Godoy-, pero con unas 130 páginas menos que este último. Así, una vez olvidados los diccionarios de Hornkens y Pallet, y tras los esfuerzos de enriquecimiento que representan los diccionarios de Oudin, Sobrino, Torre y Ocón y Herrero, el de nuestro autor se nos aparece como el precursor de los diccionarios elementales de finales del XVIII y, sobre todo, del XIX: los diccionarios manuales y de bolsillo que, destinados a un público escolar, tanta popularidad se granjearon. Sin usar aún en su portada ni en su prólogo de los términos que más tarde designarán ese tipo de diccionarios, González de Mendoza pone ya en práctica, con la primera parte de su obra, español-francés, una idea llamada a hacer fortuna con el correr del tiempo. ${ }^{17}$

\section{LA PARTE FRANCÉS-ESPAÑOL}

Lo que llevamos expuesto sobre la parte español-francés del diccionario de González de Mendoza no resulta aplicable enteramente a la segunda, francésespañol. De hecho, es la diferencia que existe entre una y otra lo que más sorprende en esta obra. Si, antes y después de González de Mendoza, la parte español-francés generalmente había sido y será de mayor extensión que la parte francés-español, en su diccionario no solo es lo contrario, sino que la parte francés-español se presenta en dos volúmenes de 468 y 566 páginas respectivamente, frente a las 368 páginas del único volumen de la parte español-francés. Pensar que esto se debe a un simple azar sería menospreciar en exceso las capacidades lexicográficas del autor, por muy limitadas que nos parezcan con respecto a las de otros lexicógrafos, especialmente en comparación con las de Sobrino.

17. Podría pensarse que eso es lo que ya intentan en cierto modo los vocabularios incorporados a obras gramaticales, incluido el de Maunory, al que ya hemos aludido. Pero las miras eran distintas. Un diccionario se presenta primeramente como obra lexicográfica, aunque pueda contener un complemento gramatical en forma de anejo o de preliminar, mientras que se trata de lo contrario en el caso de las gramáticas con vocabularios. A ello se añade la cantidad de lemas y el tipo de microestructura que contiene un diccionario frente al vocabulario reducido y la sencillez extrema de su presentación en otros tipos de obras. De hecho, los autores de vocabularios -alfabéticos o temáticos- jamás intentan comparar sus obras con los diccionarios, lo que no es el caso de González de Mendoza. 
Las dotes de González de Mendoza como lexicógrafo no son, efectivamente, calificables de excelentes. Por una parte, el diccionario de Sobrino se nos presenta como mucho más cuidado, más sistemático en la disposición general de sus artículos que el de González de Mendoza. Pero, además, frente a un Sobrino, que, por ser español o de origen español y por vivir inmerso en un ambiente francófono, dominaba perfectamente las dos lenguas que manejaba, el dominio que tenía González de Mendoza del francés parece bastante deficitario. Ciertamente, la arbitrariedad en el uso de las tildes francesas (acentos agudos, graves y circunflejos, diéresis) podría achacarse, más que al propio autor, a la falta de familiaridad de los tipógrafos madrileños con la lengua francesa; y lo mismo podría decirse de las innumerables erratas y los muchísimos atentados contra la ortografía usual, incluso simplificada, del francés de la época. ${ }^{18}$ Pero hay casos de mal uso del francés que solo pueden ser imputables a González de Mendoza. Es raro, por ejemplo, que este invente algún ejemplo en esa lengua, pero, en las ocasiones en que lo hace, y tanto en la primera como en la segunda parte, es frecuente que cometa hispanismos propios de un principiante (los resaltamos):

De què està Usted ofendida? De qua etes-vous ofensée.

No sè que hacerme. (dicho comun que en Francès es mas vulgar.) fe ne sai oú donner de la tête, aunque sin otra frase se puede decir. Fe ne sai qui faire.

Dàr verde à los cavallos. Donner le fourrage aux chevaux, lui faire manger le verd.

Lastimar, en sentido de ofender algun miembro del cuerpo (no ay) Dicese Faire du mal; v. g. me lastima un dedo, me fait de mal au doigt.

A cette Dame l'obsédent ses amans. A esta Dama la rodean, importunan, $y$ molestan sus amantes.

18. A ello se añade un orden alfabético de las entradas a menudo alterado por el cambio al que González de Mendoza sometió la forma o la ortografía usadas en los lemas por sus fuentes, sin por ello recolocar tales entradas en el nuevo lugar alfabético que les hubiera correspondido. No hablamos de casos en que el orden alfabético no es el estricto porque González de Mendoza -seguramente, de nuevo, por razones didácticas- prefería agrupar las palabras de una misma familia léxica y comenzar la serie por el masculino singular o el infinitivo, según correspondiera, sino a casos como el de la entrada francesa Quina, situada entre Quinquille y Quint simplemente porque transformó, sin más, el lema que había encontrado en su fuente (Quinquina); o la entrada española Recibir, situada entre Recio y Reclamar porque en su fuente el lema estaba ortografiado Recivir. 
Sin embargo, pese a todos estos déficits para conseguir una obra lexicográfica de calidad, no puede imputarse a ellos la desproporción que existe entre la primera y la segunda parte del diccionario de González de Mendoza. Es más, todo lleva a pensar que tal diferencia formaba parte del proyecto del autor desde el principio. De hecho, él mismo, ya desde la aparición de la primera parte -recordemos que vio la luz en 1761, dos años antes que la segunda-, anuncia en la propia portada que ambas partes no serían iguales, que la segunda sería más amplia (resaltamos):

Esta primera parte serà de Español en Frances, y la segunda de Frances en Español. Es diferente en el methodo de todos los que hasta aora se han dado al Pùblico. [...] Y ofrece completa satisfaccion en la segunda parte, donde se haràn patentes todas las voces que tiene la Lengua Francesa de que carece la Española, assi como en esta las que tiene la Española, de que carece la Francesa; $y$ serà mas estensa la explicacion de sus sentidos, y significaciones.

No es de extrañar, por consiguiente, que aluda al mismo hecho en el prólogo de esa primera parte (1761) al decir que esta no es más que un "promptuario copioso" de lo que necesita saber el lector, pero que la segunda parte "pide mas extension en su explicacion”. Por supuesto, vuelve a recordarlo en la segunda parte del diccionario (1763), cuya portada pregona su amplitud -mediante el anuncio de que la obra venía ahora "aumentada con una recopilacion de los Diccionarios de Sobrino, Occon, y Herrero"- y en cuyo prólogo se lee:

[...] confiesso es inescusable la explicacion abundante, y expressiva en las voces Francesas, que por hacer à tantas cosas, cada una dexaría ignorante ò muy dudoso à todo el que no estuviesse muy impuesto en la Lengua Francesa, sino se explicasse individualmente el sentido de cada una.

Con todo, sorprende que este segundo prólogo no incida más sobre la necesaria mayor extensión de la parte francés-español con respecto a la primera; en vez de ello, el autor opta por dedicar sus esfuerzos a vituperar abiertamente tanto el diccionario de Sobrino como a quienes lo prefieran al suyo. Se vale para ello del argumento de que Sobrino les vende también paja, mientras que él se limita a ofrecerles grano limpio a un precio inferior, por lo que quienes no sean del "bando de los tontos", para usar las palabras del autor, preferirán su diccionario al de su rival.

Es muy posible que esta insistencia se deba a que esa cuestión de precio y el ser una obra concisa y práctica desempeñaran un papel importante en la 
buena venta de la primera parte, lo que permitiría el lanzamiento de la segunda. ${ }^{19}$ Esta se vendería a un precio mayor que la primera, lo que podría justificar el empeño del autor en convencer a su potencial clientela de que, a pesar de todo, le seguía saliendo más rentable adquirir su obra antes que la de la competencia. ${ }^{20}$ No obstante, esperamos haber probado que, desde el principio, entraba en el proyecto del autor confeccionar una segunda parte francésespañol mucho más amplia que la primera. Y, puesto que no es en justificarlo en lo que más emplea sus prólogos, aunque lo haga en cierta medida, es lícito que incidamos aquí en cuál podría ser, a su entender, esa razón evidente que obligaba a un desequilibrio entre las dos partes.

Creemos que la razón principal para ello fue la del uso que se daba en su época a los diccionarios. Con la primera parte, simplemente había ofrecido un

19. Hemos visto que, desde la aparición de la primera parte, el autor debía tener ya pergeñada, si no comenzada, la segunda. En todo caso, esta última podría haber estado terminada en 1762, puesto que en mayo de ese año está fechada la licencia del Consejo para publicarla. Según el prólogo del segundo tomo, los propios editores apremiaban al autor para que terminara la segunda parte, abreviándola si fuera preciso, "porque yà no sabían que decir à los muchos que iban à buscarla, bolviendose con la respuesta mas impacientes, que persuadidos á el buen estado en que yà estaba; ello me lo ponderaron de tal modo, que sino temiera lisongearme, creyera que no podia haver cosa tan solicitada en la Corte". No descartamos que esto correspondiera a la realidad, ya que, de los dos tomos de la parte francés-español, el primero comprende las letras A-G y el segundo las letras H-Z. Pero tampoco excluimos que esto se deba al cansancio del autor o a la necesidad de abreviar con respecto a los artículos de las primeras letras para no sobrepasar un precio competitivo.

20. No sabemos a cuánto se vendía el Sobrino, dado que no se publicó en España y no contenía, por tanto, la preceptiva tasación oficial que debían incluir las obras salidas de las prensas españolas. Pero, dado lo lujoso de su edición, su gran formato y sus 601 páginas numeradas para el primer tomo y 604 para el segundo en la reedición de 1751, su precio debió de ser muy superior al del diccionario en pequeño formato de González de Mendoza. La parte español-francés de este último se vendió, según consta en la obra, a 356 maravedís (368 páginas numeradas, 44 pliegos y medio sin contar preliminares ni tablas, a ocho maravedís por pliego). No consta la tasación en la segunda parte, pero, si también se vendió a ocho maravedís por pliego, y dado que el conjunto ocupa 1034 páginas numeradas, su precio debía rondar los mil maravedís. No sería barato, pero no debería de llegar al precio del Sobrino; de ahí los esfuerzos de González de Mendoza por convencer a su clientela de que, pese a todo, esa segunda parte le convenía económicamente con respecto a la de su competidor directo, tanto más si se tomaba en cuenta el conjunto de ambas obras. Cabe comparar estos precios con los de sus predecesores españoles. El primer tomo, español-francés (1728), del diccionario de Torre y Ocón se vendió a 10 maravedís por pliego; dado que contenía 513 páginas numeradas, su precio debió de ser bastante superior al del tomo correspondiente de González de Mendoza. En cuanto al diccionario de Herrero (1744), solo unidireccional francés-español, cada pliego se tasó a seis maravedís; como solo contenía 977 páginas numeradas y era de formato similar al de González de Mendoza, seguramente se vendió a un precio superior al de la primera parte del diccionario de este, pero inferior al de los dos tomos de su parte francés-español. Por último, la parte francés-español (1731) del diccionario de Torre y Ocón, vendido a 615 maravedís (61 pliegos y medio, a diez maravedís por pliego), también debió resultar de precio inferior a la parte francés-español de González de Mendoza. Cosa distinta, naturalmente, es que sea lícito comparar estos precios sin tomar en cuenta el valor del maravedí y del coste de la vida en los años transcurridos entre 1728 y 1761. 
modo rápido - un prontuario- de solucionar problemas de expresión en francés, dado que lo dirigía esencialmente a usuarios españoles. Pero no era expresarse en francés lo que más necesitaba la generalidad de los hispanohablantes del XVIII, sino comprenderlo. Tanto los métodos de enseñanza de idiomas como las necesidades usuales del siglo llevaban hacia el desarrollo de las capacidades de comprensión de textos escritos, más que hacia las capacidades de expresión escrita u oral o de comprensión de la lengua oral extranjera. Las obras para enseñar francés a los españoles (Lépinette) siguen claramente en la época el método gramática/traducción, enfocado hacia la comprensión de la lengua escrita. En un momento en que lo novedoso llegaba a menudo a través de obras en francés, que no siempre se traducían, lo esencial era poder adquirir conocimientos leyéndolas directamente en el idioma original. De hecho, todos los diccionarios bilingües hispanofranceses de la época, como hemos mostrado en otro trabajo (Bruña Cuevas 2015a), denigran el acceso al conocimiento a través de obras traducidas y se presentan primeramente como herramientas para adquirirlo directamente de los originales. De ahí que algunos autores españoles (Herrero, Godoy y Capmany) ni siquiera se preocuparan por componer diccionarios bidireccionales: los publicaron unidireccionales francés-español porque, para los hispanohablantes, eso era lo esencial. González de Mendoza, en cierto sentido, se inserta en esta línea. Proporcionó primero una herramienta cómoda, sucinta y novedosa para desarrollar las capacidades de expresión, oral o escrita, en idioma extranjero, un prontuario muy competitivo comercialmente para lo que eran las necesidades reales de la mayor parte de los españoles que se acercaban al francés; pero la culminación de la obra, la parte verdaderamente consistente, solo podía ser la parte francés-español, la destinada a la descodificación de textos franceses, ${ }^{21}$ la realmente necesaria para todo tipo de usuarios.

21. Dos razones se nos ocurren para que González de Mendoza comenzara por la parte españolfrancés. Por un lado todos sus predecesores así lo habían hecho: siendo diccionarios editados fuera de España, los primeros compradores a los que se dirigían no eran los españoles, por lo que, para ellos, la parte esencial era la que les permitía descifrar textos escritos en español. Cierto que el de Torre y Ocón, publicado en Madrid, también se editó en 1728 con la parte español-francés, y solo en 1731 con la otra parte. Pero esta obra es póstuma. ¿Hubiera salido también la parte español-francés como tomo primero si el autor hubiera estado en vida? En todo caso, Torre y Ocón compuso primero la parte francés-español (Bruña Cuevas 2016b, 86-87). Una segunda razón, en el caso de González de Mendoza, es que, si el autor, como hemos mostrado, proyectó desde el principio dos partes de muy distinto calado, la primera era más fácil de terminar que la segunda y mucho más novedosa, ya que no existía un diccionario españolfrancés como el suyo. Era una manera, si esa primera parte tenía éxito comercial, de asegurarse la clientela para la segunda, de mayor precio. 
Esta segunda parte tenía que ser, pues, más compleja por necesidad y por posibilidades de empleo. Para comprender perfectamente un texto en francés, el usuario de un diccionario bilingüe tenía que captar exactamente el sentido del original. Ofrecerle todas las acepciones de cada palabra o expresión del idioma extranjero tenía, pues, todo su sentido. Primero, porque el contexto en que el vocablo extranjero aparecía le permitía al lector elegir el sentido preciso en que el vocablo buscado en el diccionario se estaba empleando en el texto en francés que deseaba descifrar. Segundo, porque, si se le proporcionaba para cada lema francés un buen elenco de equivalentes, su propia competencia lingüística le permitía encontrar entre ellos el más adecuado en su lengua nativa para el término o la expresión de la lengua extranjera según el contexto en que apareciera. De ahí el número de lemas, la riqueza en equivalentes y en explicaciones de toda índole de la segunda parte con respecto a la primera. Nada de esto, en cambio, era pertinente, como ya hemos dicho, en sentido inverso. El principiante que quería expresarse en francés solo necesitaba encontrar la palabra más adecuada para lo que quería decir, preferiblemente la que más se pareciera al español, ya que su esfuerzo de expresión se vería así facilitado. Ofrecerle para su vocablo español una serie de posibles términos franceses alternativos de sentido más o menos coincidente no era realmente rentable a ojos de González de Mendoza, puesto que el hispanohablante no sabría captar los posibles matices que los diferenciaban, no podría escoger el más preciso entre ellos. De ahí la condena que Mendoza hace de las series sinonímicas francesas que ofrecían los diccionarios de sus predecesores para los términos españoles, que las considerara como una complicación inútil. De ahí, en suma, la sencillez de su parte español-francés, pero la complejidad de su segunda parte francés-español: las necesidades y las posibilidades de aprovechamiento del diccionario no eran las mismas para un hispanohablante según se tratara de una o de otra; por tanto, las dos partes debían diferir radicalmente entre sí. Tal fue el principio que González de Mendoza tuvo siempre claro para la confección de su obra, un principio que supo llevar a la práctica en alto grado. No es, por tanto, falta de método, sino adaptación a las necesidades de los usuarios lo que muestra la desproporción entre ambas partes.

\section{CONCLUSIÓN}

Cada uno de los principales diccionarios que constituyen la serie histórica de la lexicografía hispanofrancesa representa una manifestación distinta de lo que 
sus autores consideraban que debía ser este tipo de obras o de lo que pensaban que necesitaban los usuarios a los que las destinaban. El diccionario de González de Mendoza es buena muestra de ello. Su principal aportación es su primera parte, español-francés, la cual representa el primer esfuerzo serio por ofrecer un diccionario manual a los españoles que, principiantes en el conocimiento del francés, deseaban expresarse en ese idioma por escrito u oralmente. Es el resultado de la identificación de un docente, o de alguien con dotes docentes, con las necesidades de los hispanohablantes que se acercaban al francés sin disponer de un nivel avanzado. Llama la atención lo diferente que es esa primera parte de la segunda, francés-español, mucho más desarrollada; pero esto, lejos de ser un defecto, indica también una toma en consideración por parte del autor de la demanda de los usuarios españoles de su tiempo, que no precisaban del mismo tipo de obra según tuvieran que pasar del español al francés o del francés al español: a necesidades diferentes, dos partes distintas en su concepción, se dijo González de Mendoza. Ciertamente, pese a la originalidad de su planteamiento, su segunda parte se parece mucho más que la primera a los diccionarios francoespañoles de su siglo, pero hasta esa parte francés-español presenta un aire diferente debido al mantenimiento de su carácter didáctico y al subjetivismo del lexicógrafo, que lo lleva incluso a adoptar en muchos artículos un estilo coloquial, casi campechano, posiblemente buscado.

Hemos de resaltar, finalmente, que el diccionario de González de Mendoza es el último testigo del esfuerzo realizado en el siglo XVIII por unos lexicógrafos españoles que sacaron los diccionarios bilingües de la dependencia de editoriales y autores extranjeros. Habrá que esperar más de cuarenta años para que -tras cinco nuevos diccionarios publicados fuera de España, cuatro de ellos por autores franceses- de nuevo Antonio de Capmany se rebele, desde posiciones explícitamente patrióticas, contra la importación de diccionarios hispanofranceses y contra su modo de composición, primordialmente pensada para francófonos. Capmany negará uno de los principios fundamentales de González de Mendoza: el de que existe gran número de voces y expresiones francesas sin equivalente exacto en español. Su propio patriotismo, su amor por el castellano y una formación sin parangón posible con la de González de Mendoza lo llevarán a ese rechazo, lo que le permitirá convertir su diccionario (Madrid 1805), por vía muy alejada de la de González de Mendoza, en un nuevo hito de la lexicografía bilingüe con el francés y el español. Pero ya el diccionario de González de Mendoza muestra anteriormente un carácter tan original para su época que ha de reconocérsele, por derecho propio, una po- 
sición relevante en la historia de la lexicografía español-francés, y ello aunque solo se tome en consideración su primera parte, precursora de los diccionarios bilingües manuales que, desde finales del XVIII y sobre todo en el XIX, tanto éxito cosecharon.

\section{OBRAS CITADAS}

Alvar Ezquerra, Manuel. "La lexicografía plurilingüe del siglo XVIII". Biblioteca virtual E-Excellence: Lengua Española. Ed. Manuel Alvar Ezquerra. Madrid: Liceus, 2005. 9 de junio de 2016. <https://aprende.liceus.com/producto/lexicografia-plurilingue-siglo-xviii/>.

Alvar Ezquerra, Manuel. Las nomenclaturas del español: siglos XV-XIX. Madrid: Liceus, 2013.

Bruña Cuevas, Manuel. "El Diccionario universal francés y español (1743) de Antonio María Herrero". La cultura del otro: español en Francia, francés en España. Eds. Manuel Bruña, María Gracia Caballos, Inmaculada Illanes, Carmen Ramírez y Anna Raventós. Sevilla: Universidad de Sevilla, 2006. 133-47.

Bruña Cuevas, Manuel. "La producción lexicográfica con el francés y el español durante los siglos XVI a XIX". Lexicografía bilingüe y plurilingüe del español (siglos XV-XIX). Ed. Manuel Bruña Cuevas. Número monográfico de Philologia Hispalensis 22 (2008a): 37-111.

Bruña Cuevas, Manuel. "El lugar de edición de los diccionarios francés-español (siglos XVI-XXI)". La lexicografía bilingüe y didáctica: ayer y hoy. Eds. Mar Campos Souto, Eva María González González y José Ignacio Pérez Pascual. La Coruña: Universidade da Coruña, 2008b. 9-20.

Bruña Cuevas, Manuel. "La traducción según los prólogos de los diccionarios francés-español (siglos XVI-XIX)". Traducción y difusión de la ciencia y la técnica en España (siglos XVI-XIX). Eds. Julia Pinilla y Brigitte Lépinette. Valencia: Universitat de València/IULMA, 2015a. 345-83.

Bruña Cuevas, Manuel. "Attitudes des auteurs des dictionnaires françaisespagnol du XVIII' siècle à l'égard de leurs sources: pourquoi les avouer ou les cacher?". Aux Marges du discours: personnes, temps, lieux, objets. Ed. Juan Manuel López Muñoz. Limoges: Lambert-Lucas, 2015b. 73-83.

Bruña Cuevas, Manuel. "La Prononciation dans les dictionnaires françaisespagnol antérieurs au XIX ${ }^{e}$ siècle". Histoire de l'enseignement de la prononciation du français aux Espagnols (XVI-XX siècles). Eds. Antonio Gaspar Galán y Javier Vicente Pérez. Berna: Peter Lang, 2016a. 83-123. 
Bruña Cuevas, Manuel. "Les Sources du dictionnaire bilingue franco-espagnol de Francisco de la Torre y Ocón (El maestro de las dos lenguas, 17281731)". Words across History: Advances in Historical Lexicography and Lexicology. Eds. María Victoria Domínguez-Rodríguez, Alicia Rodríguez-Álvarez, Gregorio Rodríguez Herrera y Verónica C. Trujillo-González. Las Palmas: Universidad de Las Palmas de Gran Canaria, 2016b. 78-90.

Bruña Cuevas, Manuel. "Las fuentes del diccionario hispanofrancés de González de Mendoza (1761-1763)”. Revista de filología románica 34.2 (2017): 299-326.

Carranza Torrejón, Ana María. "El vocabulario de la indumentaria de los siglos XVI a XIX: estudio contrastivo a partir de las nomenclaturas con el francés y el español”. Tesis doctoral. Universidad de Sevilla, 2012.

Cazorla Vivas, Carmen. "Lexicografía bilingüe de los siglos XVIII y XIX con el español y el francés". Tesis doctoral. Universidad Complutense, 2002. 10 de junio de 2016. <http://eprints.ucm.es/tesis/fll/ucm-t26053.pdf>.

Cazorla Vivas, Carmen. "Diccionarios en el Siglo de las Luces: el repertorio bilingüe de N. González de Mendoza (1761-1763)". La lexicografía bilingïe y didáctica: ayer y boy. Eds. Mar Campos Souto, Eva María González González y José Ignacio Pérez Pascual. La Coruña: Universidade da Coruña, 2008. 29-40.

Cazorla Vivas, Carmen. Diccionarios y estudio de lenguas modernas en el Siglo de las Luces: tradición y revolución lexicográfica en el ámbito hispano-francés. Madrid: Liceus, 2014.

Lépinette, Brigitte. L'Enseignement du français en Espagne au XVIII siècle dans ses grammaires: contexte bistorique, concepts linguistiques et pédagogie. Münster: Nodus, 2000.

Niederehe, Hans-Josef. "Les Dictionnaires franco-espagnols jusqu'en 1800". Histoire, Épistémologie, Langage 9.2 (1987): 13-26.

Niederehe, Hans-Josef. "Les Dictionnaires bilingues français-espagnol et espagnol-français au XVIII siècle". Travaux de linguistique et de philologie 26 (1988): 33-47.

Pablo Núñez, Luis. "Lexicografía hispano-francesa de los siglos XVI y XVII: catálogo y estudio de los repertorios". Tesis doctoral. Universidad Complutense, 2008. 2 de junio de 2016. <http://digital.csic.es/bitstream/ 10261/11298/1/LexicografiaHispanofrancesaXVI-XVII.pdf>.

Pablo Núñez, Luis. El arte de las palabras: diccionarios e imprenta en el Siglo de Oro. Mérida: Editora Regional de Extremadura, 2010. 
Zuili, Marc. "Les Mystères de l'évolution du Tesoro de las dos lenguas española y francesa de César Oudin entre 1607 et 1675". HispanismeS 3 (2014): 83100. 6 de junio de 2016. <http://www.hispanistes.fr/images/PDF/Hispanismes/Hispanismes_3/sHF\%20Hispanismes\%203\%20ZUILI\%20Marc.pdf>.

Zuili, Marc. "Étude introductive". César Oudin. Tesoro de las dos lenguas española y francesa / Tresor des deux langues françoise et espagnolle. Ed. Marc Zuili. Paris: Honoré Champion, 2016. 9-254. 